\title{
Multiple wavelength retrieval of tropospheric aerosol optical properties from MAXDOAS measurements in Beijing
}

\author{
K. Clémer ${ }^{1}$, M. Van Roozendael ${ }^{1}$, C. Fayt ${ }^{1}$, F. Hendrick ${ }^{1}$, C. Hermans ${ }^{1}$, G. Pinardi ${ }^{1}$, R. Spurr ${ }^{2}$, P. Wang ${ }^{3}$, and \\ M. De Mazière ${ }^{1}$ \\ ${ }^{1}$ BIRA-IASB, Belgian Institute for Space Aeronomy, Brussels, Belgium \\ ${ }^{2}$ RT Solutions Inc., Cambridge MA, USA \\ ${ }^{3}$ IAP/CAS, Institute of Atmospheric Physics, Chinese Academy of Sciences, Beijing, China
}

Received: 16 November 2009 - Published in Atmos. Meas. Tech. Discuss.: 7 January 2010

Revised: 31 May 2010 - Accepted: 16 June 2010 - Published: 8 July 2010

\begin{abstract}
We report on the retrieval of aerosol extinction profiles at four wavelengths from ground-based multi-axis differential absorption spectroscopy (MAXDOAS) measurements performed in Beijing, China. Measurements were made over a 10-month time period (June 2008 to April 2009) using a newly developed MAXDOAS instrument. A retrieval algorithm, based on an on-line implementation of the radiative transfer code LIDORT and the optimal estimation technique, has been designed to provide near real time information on aerosol extinction vertical profiles. The algorithm was applied to $\mathrm{O}_{4}$ measurements at four wavelengths (360, 477, 577, and $630 \mathrm{~nm}$ ). The total aerosol optical depths (AODs) calculated from the retrieved profiles exhibit higher values in spring and summer and lower values in autumn and winter. Comparison of the retrieved total AODs with values from a co-located CIMEL sunphotometer revealed a good correlation. The best results are obtained for the UV region with a correlation coefficient $(R)$ of 0.91 and a slope of the linear regression fit of 1.1. At the longest wavelength, $R$ drops down to 0.67 and the slope increases to 1.5 . The results confirm that good quality $\mathrm{O}_{4}$ slant column measurements are essential for the success of the retrievals. A method is presented to determine a correction factor to account for systematic errors. It is demonstrated that the algorithm is capable of reliably retrieving aerosol extinction profiles for a wide range of atmospheric conditions (total AODs at $360 \mathrm{~nm}$ ranging from about 0.1 to 3 ). The results open up new perspectives for the extension of the algorithm for the near real time retrieval of trace gas vertical profiles.
\end{abstract}

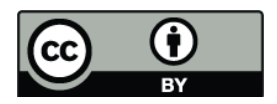

Correspondence to: K. Clémer (katrijn.clemer@aeronomie.be)

\section{Introduction}

China's rapid industrial development, urbanization, and the consequent large increase in energy consumption - primarily provided by coal-fired power plants - have resulted in an alarming deterioration of air quality. This increased air pollution is particularly problematic in megacities such as Beijing, where the presence of elevated concentrations of pollutants such as $\mathrm{NO}_{2}, \mathrm{SO}_{2}$, ozone and fine particles entails serious health risks for the population. Moreover, through long-distance transport, air pollution in China has a potential impact on a global scale. It has been shown also that changes in the concentration and composition of atmospheric aerosol strongly influence the energy balance of the climate system (IPCC, 2007). Aerosol can scatter and absorb sunlight, thereby altering the Earth's radiation budget. In a more indirect way, aerosol can influence climate change through their effects on cloud formation, composition and precipitation. Consequently, long-term ground-based measurements providing information on the total column and on the vertical distribution of tropospheric aerosol and trace gases are indispensable. Such time series can be used to monitor the evolution of air pollution, to evaluate the direct effect of measures taken to improve air quality, and to validate air quality models and satellite observations.

Over the past decade, ground-based multi-axis differential optical absorption spectroscopy (MAXDOAS) has been shown to be a very promising tool for the automated retrieval of tropospheric pollutants (Hönninger et al., 2004; Wagner et al., 2004; Wittrock et al., 2004; Friess et al., 2006; Li et al., 2010; Irie et al., 2009). MAXDOAS instruments are designed to perform quasi-simultaneous observations of scattered sunlight for a range of different line-of-sight (LOS)

Published by Copernicus Publications on behalf of the European Geosciences Union. 


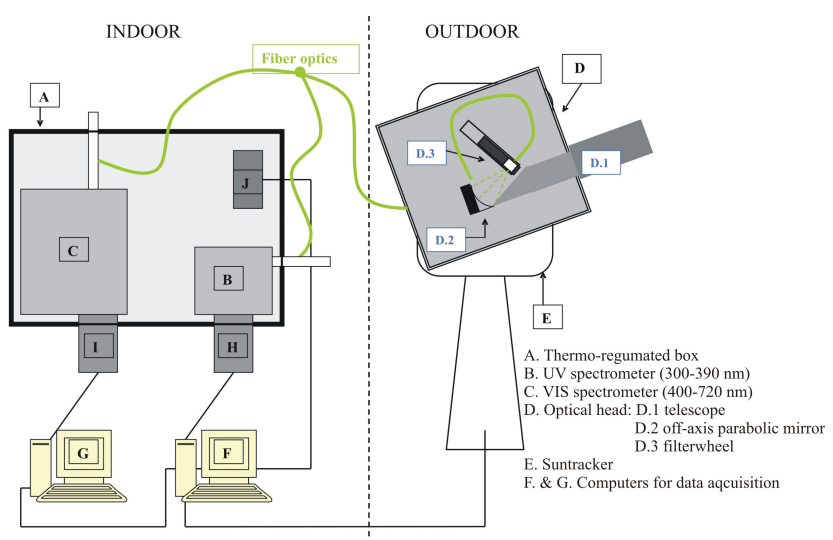

Fig. 1. Schematic view of the MAXDOAS instrument.

directions from the horizon to the zenith, resulting in an increased sensitivity towards atmospheric absorbers such as $\mathrm{NO}_{2}$ that are present in the lower troposphere. However, the observed trace gas absorptions depend not only on the absorption cross-section and vertical distribution of the trace gas, but also on the presence of tropospheric aerosol. The aerosol influence the length of the light path and consequently the observed trace gas absorptions. The latter dependency makes MAXDOAS measurements suitable for the retrieval of aerosol properties. At the same time, the retrieval of aerosol properties from the MAXDOAS measurement becomes a necessity to enable the retrieval of trace gas vertical profiles (Wittrock et al., 2004; Heckel et al., 2005; Sinreich et al., 2005).

It has been demonstrated conclusively that aerosol information can be derived from differential absorption measurements of $\mathrm{O}_{4}$ (Wagner et al., 2004; Friess et al., 2006). The $\mathrm{O}_{4}$ cross-section exhibits four main absorption bands in the UVVIS region of the electromagnetic spectrum with maxima at around $360,477,577$, and $630 \mathrm{~nm}$. The vertical profile of the $\mathrm{O}_{4}$ concentration is well-known and nearly constant (depending mainly on temperature and pressure), i.e., $\mathrm{O}_{4}$ is the collision complex of $\mathrm{O}_{2}$ and thus its concentration is proportional to the square of the $\mathrm{O}_{2}$ concentration. The profile exhibits a marked peak at the surface (Greenblatt et al., 1990). With $\mathrm{O}_{4}$ concentrated mainly near the surface, the observed $\mathrm{O}_{4}$ absorption is very sensitive to changes in the light path distribution due to the presence of aerosol at low altitudes (Friess et al., 2006).

In this paper, we report on the application of a new retrieval algorithm developed for near real time automated retrieval of aerosol extinction vertical profiles on MAXDOAS measurements made in Beijing during the June 2008-April 2009 period. The paper consists of three main sections. In the first part, we describe the MAXDOAS instrument that was installed in Beijing and the measurements to which the retrieval algorithm was applied. The second section describes the retrieval algorithm and the specific settings ap- propriate to a heavily polluted scenario, such as observed in Beijing. In the third section, we show the results of the application of the retrieval algorithm on the MAXDOAS measurements and discuss the information content and error budget of the retrievals. We also present comparisons of the retrieved total aerosol optical depths (AODs) with correlative data from a co-located CIMEL sunphotometer.

\section{MAXDOAS measurements}

To monitor air quality and support the validation of satellite observations of tropospheric pollutants, a MAXDOAS instrument was installed on the roof of the Institute of Atmospheric Physics (IAP) of the Chinese Academy of Sciences (CAS), a few hundred meters from the Beijing Olympic sta$\operatorname{dium}\left(39^{\circ} 58^{\prime} 37^{\prime \prime} \mathrm{N} 116^{\circ} 22^{\prime} 51^{\prime \prime} \mathrm{E}\right)$. The instrument was operated continuously from July 2008 to April 2009.

\subsection{The instrument}

This "state-of-the-art" MAXDOAS instrument, optimized for the retrieval of tropospheric aerosol and trace gas properties, was designed and assembled at the Belgian Institute for Space Aeronomy (BIRA-IASB). The instrument is shown schematically in Fig. 1. It consists of three main parts: a thermo-regulated box (Fig. 1, A) containing two spectrometers (Fig. 1, B and C) located inside the building, the optical head (Fig. 1, D) mounted on a suntracker (Fig. 1, E) located outside and connected to the spectrometers via optical fibers, and the controlling and acquisition unit (Fig. 1, F and G).

The MAXDOAS instrument is a dual-channel system. Three optical fibers with rectangular terminations connected through a fiber optic splitter link the output of the optical head with the two spectrometers. The optical head design is such that the telescope (Fig. 1, D.1) can be moved over a wide range of elevations $\left(0-90^{\circ}\right)$, as well as azimuth directions $\left(0-360^{\circ}\right)$. The optical head is mounted on a commercial sun tracker from the BRUSAG company (INTRA). This setup enables us not only to measure scattered light, but also to take direct-sun measurements. Skylight is collected by an off-axis parabolic mirror (Fig. 1, D.2) within a $0.8^{\circ}$ field of view. The optical head also includes a 6-position filter wheel (Fig. 1, D.3) equipped with transmission diffuser plates and neutral density filters.

The optical head collects direct-sun and scattered light at various elevation and azimuth angles. The light is guided to the two spectrometers through optical fibers. The first spectrometer (Fig. 1, B), a commercial grating spectrometer from ORIEL (model MS260i), covers the UV region (300$390 \mathrm{~nm}$ ). The grating consists of 1200 grooves $/ \mathrm{mm}$ blazed at $350 \mathrm{~nm}$. The instrument function is close to a Gaussian with a full width at half maximum (FWHM) equal to $0.4 \mathrm{~nm}$, and there is good sampling (9 pixels at mid-height for the $\mathrm{Hg}$ line at $346 \mathrm{~nm}$ ). A bandpass filter (U340 HOYA) is used to 
block the visible light at the entrance slit of the spectrometer and hence to reduce stray-light effects in the UV region. The output of the spectrometer is connected to a low-noise thermo-electrically cooled (to $233 \mathrm{~K}$ ) CCD detector system (Princeton Instruments, model PIXIS 2KBUV, back illuminated, UV enhanced) with $2048 \times 512$ pixels (Fig. $1, H)$. The spectral range covered by the second spectrometer (ORIEL MS127) extends from $400 \mathrm{~nm}$ to $720 \mathrm{~nm}$ (Fig. 1, C). The detector (Fig. 1, I) is a back illuminated CCD (Princeton Instruments, model Spec-10: 100B). It has $1340 \times 100$ pixels and is kept at $235 \mathrm{~K}$ by means of a Pelletier cooling system. The grating consists of 600 grooves $/ \mathrm{mm}$ blazed at $400 \mathrm{~nm}$. The instrument function is close to a Gaussian with FWHM $0.9 \mathrm{~nm}$. To block the UV light produced at the second order of diffraction which interferes with visible light diffracted in the first order, a low-pass filter (CVI-Melles Griot with a cutoff at $395 \mathrm{~nm}$ ) is used. The whole system is mounted inside a thermally regulated (Fig. 1, J) container to minimize thermal stress on mechanical and optical parts.

The controlling unit consists of two synchronized computers. A first "master" computer controls the sun tracker (i.e., elevation and azimuth angle of the telescope), the filter wheel and the acquisition of spectral data from the spectrometer operating in the UV region. The second "slave" computer does a synchronized acquisition of the spectral data from the spectrometer operating in the VIS region. The data acquisition is fully automated using software developed at BIRA-IASB.

During the Beijing campaign, the telescope pointed north (and thus to a fixed azimuth direction) for the MAXDOAS measurements. A full MAXDOAS scan comprised 9 elevation angles $\left(2^{\circ}, 4^{\circ}, 6^{\circ}, 8^{\circ}, 10^{\circ}, 12^{\circ}, 15^{\circ}, 30^{\circ}\right.$, zenith $)$ and required approximately $15 \mathrm{~min}$ measurement time.

\subsection{The DOAS retrieval}

The measured spectra of scattered sunlight are analysed using the DOAS technique (Platt, 1994; Platt and Stutz, 2008), based on a least-squares spectral fitting method implemented in the WinDOAS computer software (Van Roozendael et al., 1999; Fayt and Van Roozendael, 2001). The direct results of this fitting are the differential slant column densities (DSCDs), i.e. the integrated concentrations of the absorbers along the effective light path of the scattered photons relative to the concentrations of the absorbers corresponding to a measured reference spectrum. For tropospheric profiling purposes, one can eliminate the stratospheric contribution to the measured DSCD by subtracting for each scan the DSCD measured at zenith from the off-axis DSCDs (Hönninger, 2004). This approach is widely used for the retrieval of trace gas profiles from MAX-DOAS measurements and was adopted here for the aerosol retrievals even though the $\mathrm{O}_{4}$ is mainly located in the troposphere. The advantage being that by using a reference measured shortly after the off-axis DSCDs, we can assume that the aerosol extinction profile is mainly identical for both measurements facilitating the in- terpretation (Friess et al., 2006). The $\mathrm{O}_{4}$ DSCDs, needed for the aerosol extinction profile retrieval, are retrieved in four different wavelength intervals. One interval in the UV region of the electromagnetic spectrum $(338-370 \mathrm{~nm})$, and three in the VIS region (425-490 nm, 540-588 nm, and 602$645 \mathrm{~nm}$ ) were selected. Each of these intervals captures one of the main $\mathrm{O}_{4}$ absorption lines. Mean interval wavelengths, weighted with the appropriate $\mathrm{O}_{4}$ absorption cross-section, correspond to the maxima of the $\mathrm{O}_{4}$ absorption at 360,477 , 577 , and $630 \mathrm{~nm}$. Figure 2 gives an example of the $\mathrm{O}_{4}$ fits and residuals. In addition to the $\mathrm{O}_{4}$ cross-section, other trace gas cross-sections for $\mathrm{NO}_{2}, \mathrm{O}_{3}, \mathrm{H}_{2} \mathrm{O}, \mathrm{HCHO}, \mathrm{BrO}$, and $\mathrm{O}_{2}$ were included in the fitting, along with a Ring spectrum (Chance and Spurr, 1997) and a low-order polynomial closure term. In Table 1 an overview is given of the different trace gas cross sections and the polynomial included for the different wavelength intervals.

Wavelength regions were chosen to obtain optimal sensitivity for $\mathrm{O}_{4}$ while minimizing interference from other absorption signatures. For the two intervals at longer wavelength, the presence of strong $\mathrm{H}_{2} \mathrm{O}$ absorption structures can significantly hamper the DOAS fitting. Therefore, we opt for fitting intervals centered at 577 and $630 \mathrm{~nm}$ that are relatively short compared to the width of the corresponding $\mathrm{O}_{4}$ absorption band in order to minimize interference by $\mathrm{H}_{2} \mathrm{O}$ absorption towards the outer limits of the intervals. Using the relatively short fitting ranges substantially improved the residual and reduced DOAS fitting errors. Consequently, however, the $\mathrm{O}_{4}$ absorption bands at 577 and $630 \mathrm{~nm}$ are not fully covered, as can be seen from Fig. 2. This increases the risk that errors are induced in the retrieved $\mathrm{O}_{4}$ DSCDs caused by the interference from correlated absorbers. Also, even with the short wavelength intervals, there are still interfering $\mathrm{H}_{2} \mathrm{O}$ structures present. These $\mathrm{H}_{2} \mathrm{O}$ absorptions are very difficult to fit as the effective absorption cross-section depends on the $\mathrm{H}_{2} \mathrm{O}$ concentration due to saturation. Small misfits between the observed $\mathrm{H}_{2} \mathrm{O}$ absorptions and the $\mathrm{H}_{2} \mathrm{O}$ cross-section used in the DOAS fitting increase the residual, as illustrated in Fig. 2, and can induce unwanted errors in the $\mathrm{O}_{4}$ DSCD. At $630 \mathrm{~nm}$, there is additional interference from $\mathrm{O}_{2}$ absorption lines, resulting in a residual of almost $0.5 \%$ and an $\mathrm{O}_{4}$ DSCD DOAS fit error 4 times higher than that for the other wavelength windows.

Several $\mathrm{O}_{4}$ cross-sections have been reported in the literature (Perner and Platt, 1980; Greenblatt et al., 1990; Volkamer, 1996). We decided to use the Hermans $\mathrm{O}_{4}$ cross-section (http://www.aeronomie.be/spectrolab/o2.htm) in the DOAS analysis, as the shapes of the main absorption lines fitted well the observed $\mathrm{O}_{4}$ absorption features, as illustrated in Fig. 2. In the DOAS analysis, both the shape and the absolute values of the cross-sections influence the retrieved DSCD. Cross-sections reported in the literature not only display slightly different shapes, but also their absolute values are quite different, e.g., the peak cross-section of the $\mathrm{O}_{4}$ absorption band around $360 \mathrm{~nm}$ ranges from $4.24 \mathrm{e}-46$ 
Table 1. DOAS retrieval settings.

\begin{tabular}{lccccl}
\hline & $338-370 \mathrm{~nm}$ & $425-490 \mathrm{~nm}$ & $540-588 \mathrm{~nm}$ & $602-645 \mathrm{~nm}$ & Reference \\
\hline $\mathrm{O}_{4}$ & $\times$ & $\times$ & $\times$ & $\times$ & Hermans \\
$\mathrm{NO}_{2} 298 \mathrm{~K}$ & $\times$ & $\times$ & $\times$ & $\times$ & Van Daele et al. (1998) \\
$\mathrm{NO}_{2} 220 \mathrm{~K}$ & & $\times$ & $\times$ & & Van Daele et al. (1998) \\
$\mathrm{O}_{3} 223 \mathrm{~K}$ & $\times$ & $\times$ & & & Bogumil et al. (2003) \\
$\mathrm{BrO} 228 \mathrm{~K}$ & $\times$ & & & Wilmouth et al. (1999) \\
$\mathrm{HCHO}$ & $\times$ & $\times$ & $\times$ & Meller and Moortgat (2000) \\
$\mathrm{H}_{2} \mathrm{O}$ & & & & & HITRAN (Rothman et al., 2009) \\
$\mathrm{O}_{2}$ & & order 2 & order 3 & order 3 & \\
Polynomial & order 3 & HITRAN (Rothman et al., 2009) & \\
\hline
\end{tabular}

a http://www.aeronomie.be/spectrolab/O2.htm
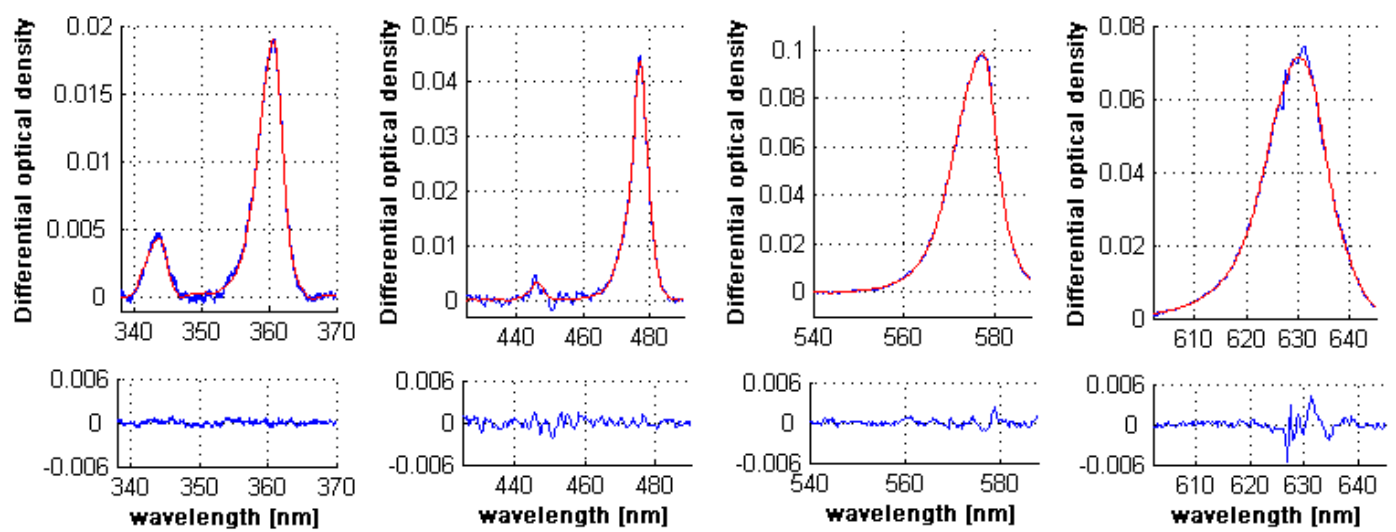

Fig. 2. Example of an $\mathrm{O}_{4}$ fit in four wavelength intervals used in this study, as recorded in Beijing on 15 November 2008 at 06:15:00 UTC. The $\mathrm{O}_{4}$ DSCDs and DOAS fit errors are $(4.46 \pm 0.013),(6.75 \pm 0.023),(9.03 \pm 0.021),(10.1 \pm 0.14) \times 10^{43} \mathrm{molec}^{2} / \mathrm{cm}^{5}$ for the wavelength intervals centered around $360,477,577$, and $630 \mathrm{~nm}$, respectively.

to $5.4 \mathrm{e}-46 \mathrm{molec}^{-2} \mathrm{~cm}^{5}$ (Wagner et al., 2002). The peak value of the Hermans $\mathrm{O}_{4}$ cross-section around $360 \mathrm{~nm}$ is $4.29 \mathrm{e}-46 \mathrm{molec}^{-2} \mathrm{~cm}^{5}$.

As a consistency check, we compared the $\mathrm{O}_{4}$ DSCDs measured on clear-sky days with low aerosol load (total $\mathrm{AOD}<0.15)$ with $\mathrm{O}_{4}$ DSCDs simulated using a radiative transfer model with inputs taken from retrieved aerosol profiles and ancillary aerosol information. Under these conditions, the $\mathrm{O}_{4}$ DSCDs at $15^{\circ}$ and $30^{\circ}$ elevation angle are rather insensitive to changes in the atmospheric parameters (pressure, temperature) or aerosol optical properties (Friess et al., 2006; Wagner et al., 2009). This is illustrated in Fig. 3, which displays the diurnal variation of simulated $\mathrm{O}_{4}$ DSCDs at $30^{\circ}$ elevation for an aerosol profile exponentially decreasing with altitude, for different total AODs and scaling heights. Consequently, good agreement is expected between the measured and simulated $\mathrm{O}_{4}$ DSCDs at $15^{\circ}$ and $30^{\circ}$ elevation. However, we noticed, that the simulated $\mathrm{O}_{4}$ DSCDs were systematically lower. It is possible that these differences are induced during the DOAS retrieval, because of uncertainties in the absolute values of the $\mathrm{O}_{4}$ cross-sections. Also the temperature and pressure dependencies of the $\mathrm{O}_{4}$ absorption cross-section is not well known (Wagner et al., 2002). To account for this, we retrieved a correction factor for the measured $\mathrm{O}_{4}$ DSCDs as follows.

For a selection of clear-sky days with a low aerosol load, $\mathrm{O}_{4}$ DSCDs were simulated for an aerosol profile exponentially decreasing with altitude, with a scaling-height of $0.5 \mathrm{~km}$, and a total aerosol optical depth as measured by a co-located sunphotometer (Holben et al., 1998) (more details about the CIMEL instrument can be found in Sect. 3.2). Comparing the measured and simulated $\mathrm{O}_{4}$ DSCDs at $15^{\circ}$ and $30^{\circ}$ elevation, we found that values of the simulated DSCDs were systematically $(25 \pm 10) \%$ smaller than the measured ones, as illustrated in Fig. 4. The same factor was found for all wavelengths. To account for this difference, the measured $\mathrm{O}_{4}$ DSCDs were modified according to the following:

$\mathrm{DSCD}_{\text {corrected }}=\mathrm{DSCD}_{\text {uncorrected }} \cdot 0.8$.

A similar correction factor has been previously reported by Wagner et al. (2009). From now on, unless stated differently, 

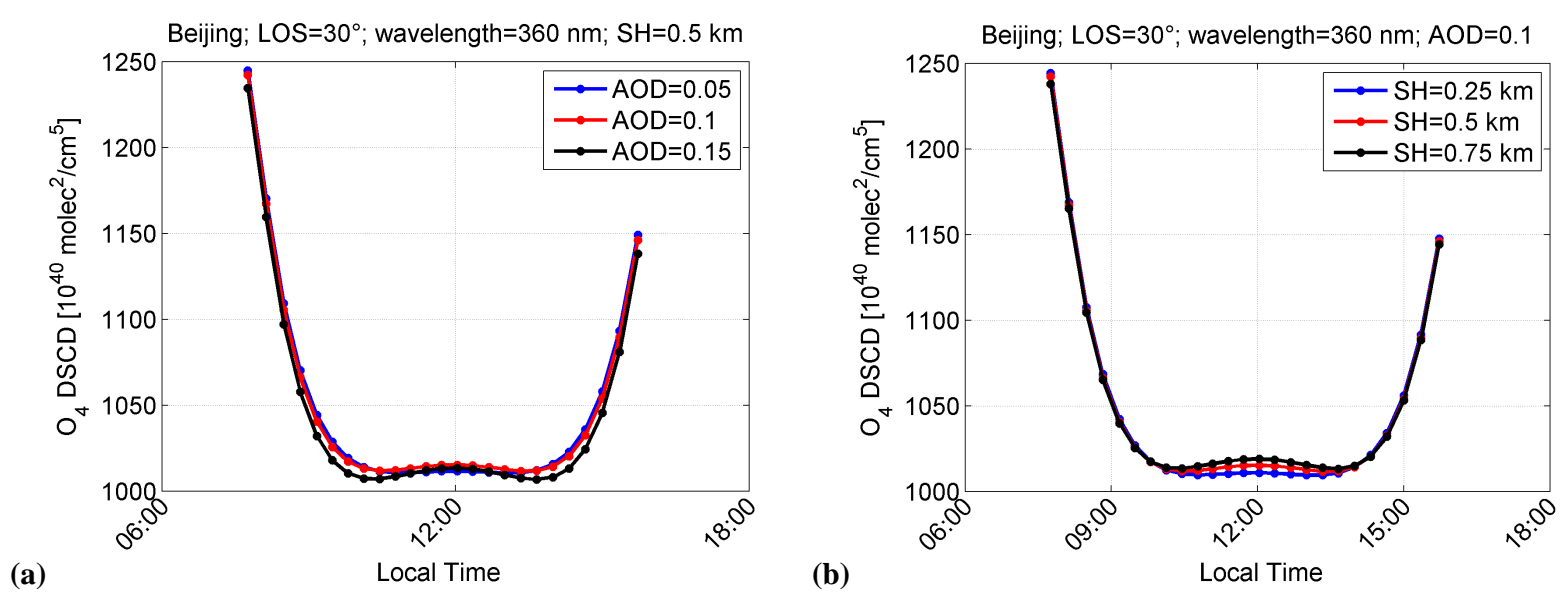

Fig. 3. Diurnal variation of simulated $\mathrm{O}_{4}$ DSCDs at $30^{\circ}$ elevation at $360 \mathrm{~nm}$ for an aerosol profile exponentially decreasing with altitude: (a) With a scaling height of $0.5 \mathrm{~km}$ for different aerosol optical depths $(0.05-1.5)$ and (b) with an aerosol optical depth of 0.1 and different scaling heights $(0.25-0.75 \mathrm{~km})$.

the $\mathrm{O}_{4}$ DSCDs mentioned in this paper refer to the corrected DSCDs.

\section{Aerosol extinction retrieval}

An inversion algorithm was developed, dedictated for the retrieval of aerosol extinction profiles at different wavelengths from MAXDOAS measurements. A schematic representation of the algorithm is depicted in Fig. 5. In the next section, we give a brief description of the algorithm and discuss specific settings used for the profile inversion from MAXDOAS measurements made in Beijing.

\subsection{General algorithm description}

The aerosol extinction vertical profile is retrieved from a set of measurements, which in our case is a set of fitted $\mathrm{O}_{4}$ DSCDs for different LOS directions in one DOAS scan. In general, the length of the light path through the atmosphere (and thus the observed DSCD of an atmospheric absorber) depends not only on the concentration of the absorber, but also on the vertical distribution and optical properties of the aerosol present in the atmosphere. Consequently, when the vertical distribution of an absorber is well known and nearly constant - the $\mathrm{O}_{4}$ concentration varies with the square of the $\mathrm{O}_{2}$ monomer - DSCD measurements provide information on the aerosol optical properties (Hönninger et al., 2004; Wagner et al., 2004; Friess et al., 2006).

The information content of the measurement vector $(\boldsymbol{y})$ of fitted $\mathrm{O}_{4}$ DSCDs from one MAXDOAS scan is too small to yield a unique solution for the aerosol extinction vertical profile $(\boldsymbol{x})$; in other words, the problem is ill-posed. Therefore, we use the Optimal Estimation Method (OEM; Rodgers, 2000) for the inversion. In this approach the nec- essary ad-hoc information is added in the form of an a priori profile $\left(\boldsymbol{x}_{\mathrm{a}}\right)$ and its uncertainty covariance matrix $\left(\mathbf{S}_{\mathrm{a}}\right)$. The measurement error is expressed by the measurement uncertainty covariance matrix $\left(\mathbf{S}_{\varepsilon}\right)$. The non-linear aerosol inversion problem can then be solved in an iterative way as expressed by the equation:

$$
\begin{aligned}
\boldsymbol{x}_{i+1}= & \boldsymbol{x}_{i}+\left(\mathbf{S}_{a}^{-1}+\mathbf{K}_{i}^{\mathrm{T}} \mathbf{S}_{\varepsilon}^{-1} \mathbf{K}_{i}\right)^{-1}\left[\mathbf{K}_{i}^{\mathrm{T}} \mathbf{S}_{\varepsilon}^{-1}\left(\boldsymbol{y}-\mathbf{F}\left(\boldsymbol{x}_{i}\right)\right)\right. \\
& \left.-\boldsymbol{S}_{\boldsymbol{a}}^{-\mathbf{1}}\left(\boldsymbol{x}_{\boldsymbol{i}}-\boldsymbol{x}_{\boldsymbol{a}}\right)\right]
\end{aligned}
$$

where the superscripts $\mathrm{T}$ and -1 denote the transposed and the inversed matrix, respectively. This approach requires a forward model (F), implemented as a numerical model describing the physics of the measurement, and a weighting function matrix $(\mathbf{K})$, expressing the sensitivity of the measurements to changes in the aerosol extinction profile. The forward model in our application is based on the linearized discrete ordinate radiative transfer model (LIDORT) (Spurr, 2008). One major advantage of this code is that it includes an analytical calculation of the weighting functions needed for the inversion step. The algorithm is fast enough to allow for near real time automated retrievals without the need for look-up table calculations.

The relationship between the retrieved, the true $\left(\boldsymbol{x}_{\text {true }}\right)$, and the a priori aerosol extinction profile can be expressed as follows (Rodgers, 2000)

$\boldsymbol{x}=\boldsymbol{x}_{\mathrm{a}}+\mathbf{A}\left(\boldsymbol{x}_{\text {true }}-\boldsymbol{x}_{\mathrm{a}}\right)$

The matrix A expresses the sensitivity of the retrieved to the true state. The columns of $\mathbf{A}$ are the averaging kernels, and the trace of $\mathbf{A}$ the degrees of freedom of signal (DFS), which expresses the number of independent pieces of information that can be extracted from the retrieval. For an ideal retrieval case, $\mathbf{A}$ is the unity matrix, the averaging kernels are 

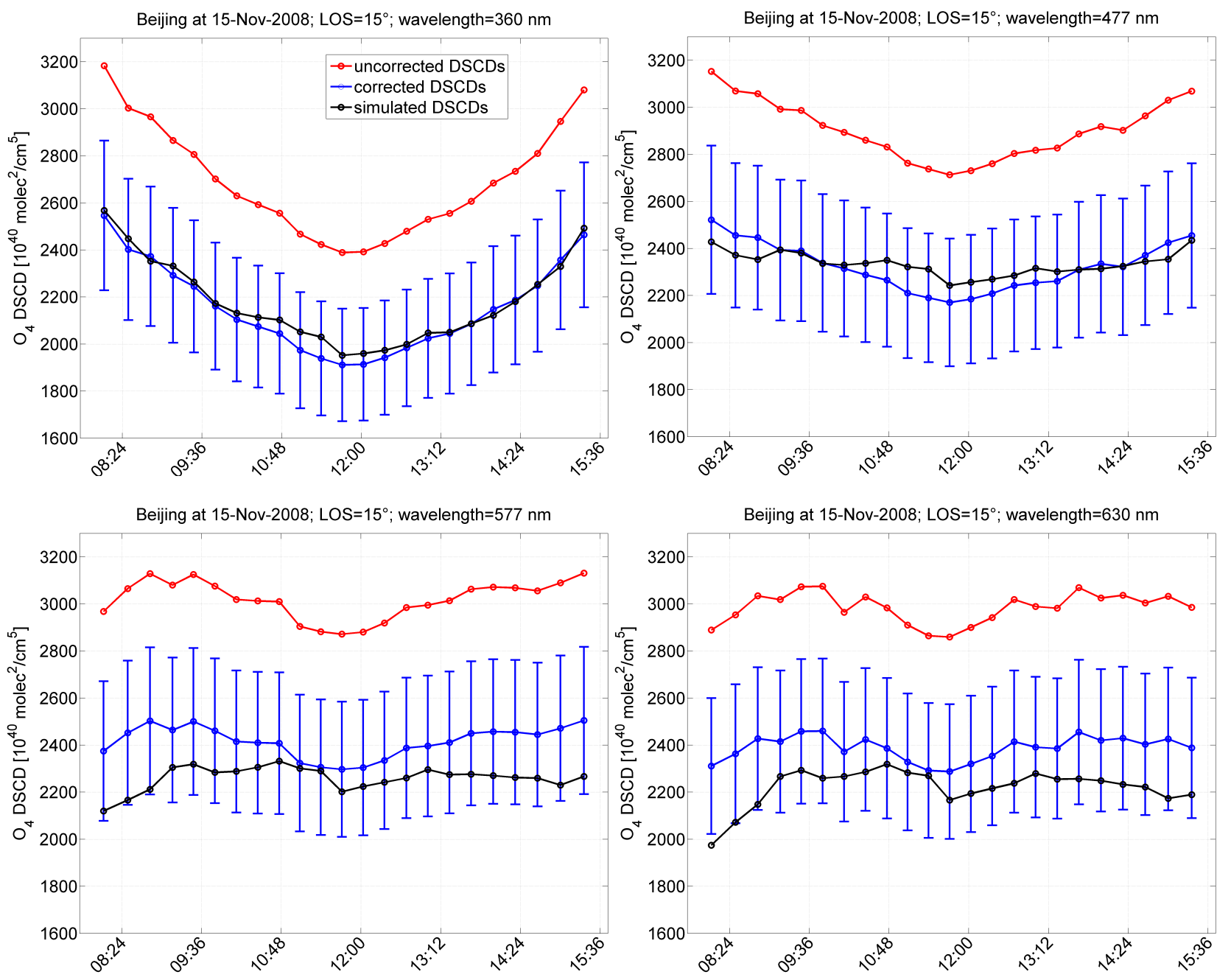

Fig. 4. The diurnal variation of the simulated $\mathrm{O}_{4}$ DSCDs and the uncorrected and corrected $\mathrm{O}_{4}$ DSCDs for $15^{\circ}$ elevation on 15 November 2010 in Beijing.

delta functions peaking at the corresponding altitudes, and the DFS equals the number of retrieved profile layers. In reality, the retrieved profile is a smoothed version of the real profile. The vertical resolution of the retrieval at a certain altitude can be estimated from the FWHM of the main peak of the corresponding averaging kernel.

The quality of the retrieved profiles is also determined by the total uncertainties of the state vector elements (Rodgers, 2000). The total error can be separated into three components: (1) the error due to the smoothing of the true profiles (determined by $\mathbf{S}_{\mathrm{a}}$ ); (2) the error caused by the random and systematic errors in the measurements $\left(\mathbf{S}_{\varepsilon}\right)$; (3) the error due to systematic errors in the forward model (caused by uncertainties in the parameters determining the atmosphere). $\mathbf{K}$ depends on the aerosol profile and therefore changes at each iteration step of the optimal estimation. Also, the matrix $\mathbf{S}_{\mathrm{a}}$ is constructed such that it depends on the aerosol profile (see Sect. 3.2 below for more details). We used $\mathbf{K}$ and $\mathbf{S}_{\mathrm{a}}$ from the final iteration step to calculate $\mathbf{A}$ and the final retrieval errors.

The relative intensity measurements [intensity(offaxis)/intensity(zenith)] also contain information on aerosol optical properties. Hence as suggested by Friess et al. (2006), including these intensities in the measurement vector $\boldsymbol{y}$ could possibly increase the DFS of the retrieval. However, there are a number of complicating issues that need to be considered: (1) the intensities are more sensitive to the presence of clouds than the $\mathrm{O}_{4}$ DSCDs, (2) the intensities are more sensitive to errors in the parameters determining the atmosphere (e.g., surface albedo, aerosol single scattering albedo and phase function) than the $\mathrm{O}_{4}$ DSCDs, and (3) for accurate simulation of the intensities, polarization needs to be included in the radiative transfer (RT). The latter is illustrated in Fig. 6, based on simulations performed using the Doubling Adding KNMI (DAK) radiative transfer model (de Haan, 1987; Stammes, 2001). The 
effect of polarization strongly depends on the solar angles and viewing geometry. Neglecting polarization can give rise to a systematic error of up to $15 \%$ for the intensities. The $\mathrm{O}_{4}$ DSCDs are less sensitive to polarization (errors up to 5\%). It should be noted that this effect cannot account for the observed difference between the measured and simulated $\mathrm{O}_{4}$ DSCDs as discussed in Sect. 2.2. Because of these points and since including polarization would substantially increase the time needed for RT calculations, we decided not to include intensities in the present work. In a future study we might explore whether, for specific clear sky cases the inclusion of intensities can lead to a further improvement of the information content of our retrievals. In addition including the intensities might enable the retrieval of atmospheric parameters for which these quantities are more sensitive than the $\mathrm{O}_{4}$ DSCDs.

\subsection{Retrieval parameter settings}

With optimal estimation, choices of the a priori profile and error covariance matrices have important impacts on the results. There is a trade-off between maximizing the DFS and eliminating the occurrence of spurious oscillations in the retrieved profiles.

For the retrieval of aerosol extinction profiles, we assume that the correction factor applied on the measured $\mathrm{O}_{4}$ DSCDs (Sect. 2.2) eliminates most systematic errors on the measurements. In this way, $\mathbf{S}_{\varepsilon}$ is then a diagonal matrix, with variances equal to the square of the DOAS fitting error. From the averaging kernels, it was seen that the sensitivity decreases drastically over 1 to $2 \mathrm{~km}$ (see Sect. 3.3 below for details), depending on the height of the aerosol layer. Therefore we retrieved a profile for the first $4 \mathrm{~km}$ of the troposphere only. Partial columns were retrieved every $200 \mathrm{~m}$ up to $2 \mathrm{~km}$. At higher altitudes, two partial columns of $500 \mathrm{~m}$ between 2 and $3 \mathrm{~km}$ and one partial column of $1 \mathrm{~km}$ between $3 \mathrm{~km}$ and $4 \mathrm{~km}$ were retrieved. In total the retrieved profile consisted of 13 layers.

In principle, the a priori profile should be a reasonable estimate of the true profile. A priori information is often taken from climatology. However, in Beijing, the total AOD can change very rapidly in time over a large range (total AOD from 0.1 to 3 ). In addition, very little is known about the expected aerosol extinction profile shape, making it difficult to get a reliable first estimate of the true profile. Therefore, we chose a fixed a priori (taken from the LOWTRAN climatology) with a total AOD of 0.1. As the total AOD of the true profile can deviate strongly from the a priori, the covariance matrix $\mathbf{S}_{\mathrm{a}}$ needs to be constructed so as to allow for these large variations and at the same time to avoid the occurrence of spurious oscillations. In view of these requirements, $\mathbf{S}_{\mathrm{a}}$ was constructed as follows: The diagonal element corresponding to the lowest layer, $\mathbf{S}_{\mathrm{a}}(1,1)$, is set equal to the square of a scaling factor $\beta$ times the maximum partial AOD of $\boldsymbol{x}_{i}$. The other diagonal elements decrease linearly with

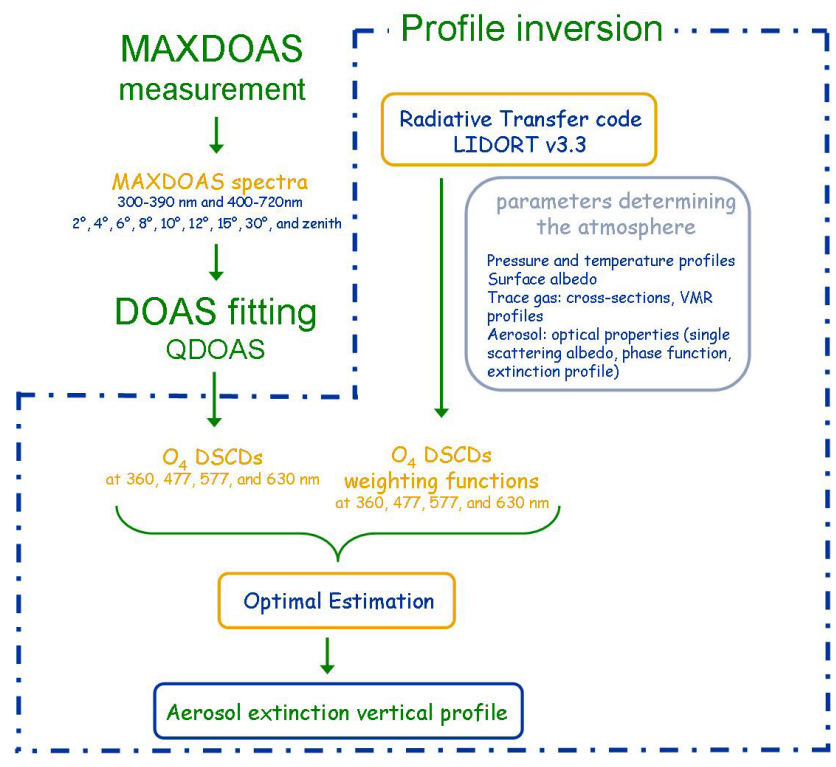

Fig. 5. Flow chart for the aerosol extinction profile retrieval process.

altitude down to $0.2 \times \mathbf{S}_{\mathrm{a}}(1,1)$. In this way, $\mathbf{S}_{\mathrm{a}}$ changes for each iteration, allowing the AOD of the retrieved profile to deviate strongly from the a priori for cases with a large total AOD. On the other hand, for profiles with a smaller total AOD, the diagonal elements of $\mathbf{S}_{\mathrm{a}}$ show less variation. The scaling factor $\beta$ can be adjusted depending on the instrument $\left(\mathbf{S}_{\varepsilon}\right)$ and location (AOD variability). For the measurements in Beijing, the best results were obtained for $\beta=0.2$. It should be noted, however, that when using this approach, the underlying statistics of the retrieval algorithm are no longer Bayesian. The off-diagonal terms in $\mathbf{S}_{\mathrm{a}}$, introducing profile correlations at different altitudes, were set using Gaussian functions as follows: (Barret et al., 2002; Friess et al., 2006)

$\mathbf{S}_{\mathrm{a}}(i, j)=\sqrt{\mathbf{S}_{\mathrm{a}}(i, i) \mathbf{S}_{\mathrm{a}}(j, j) \exp \left(-\ln (2)\left(\frac{\left(z_{i}-z_{j}\right)}{\gamma}\right)^{2}\right)}$,

where $z_{i}$ and $z_{j}$ are the altitudes of $i$-th and $j$-th levels, respectively. The correlation length $\gamma$ is set to $0.05 \mathrm{~km}$ to optimize the DFS. This optimization was done using the empirical method reported by Hendrick et al. (2004).

The $\mathrm{O}_{4}$ DSCDs calculated using the forward model not only depend on the aerosol optical properties but also on other parameters such as the pressure and temperature profiles, the surface albedo and other trace gas $\left(\mathrm{NO}_{2}, \mathrm{O}_{3}\right)$ profiles. With no local information available, we used the US standard profiles for the pressure, temperature and trace gas profiles. Errors in these parameters only have a small effect on the simulated DSCDs (Friess et al., 2006; Irie et al., 2008). A Lambertian surface albedo of 7\%, acceptable for the Beijing area (Koelemeijer, 2003), was used. We neglected any wavelength dependency or seasonal variability of the surface 

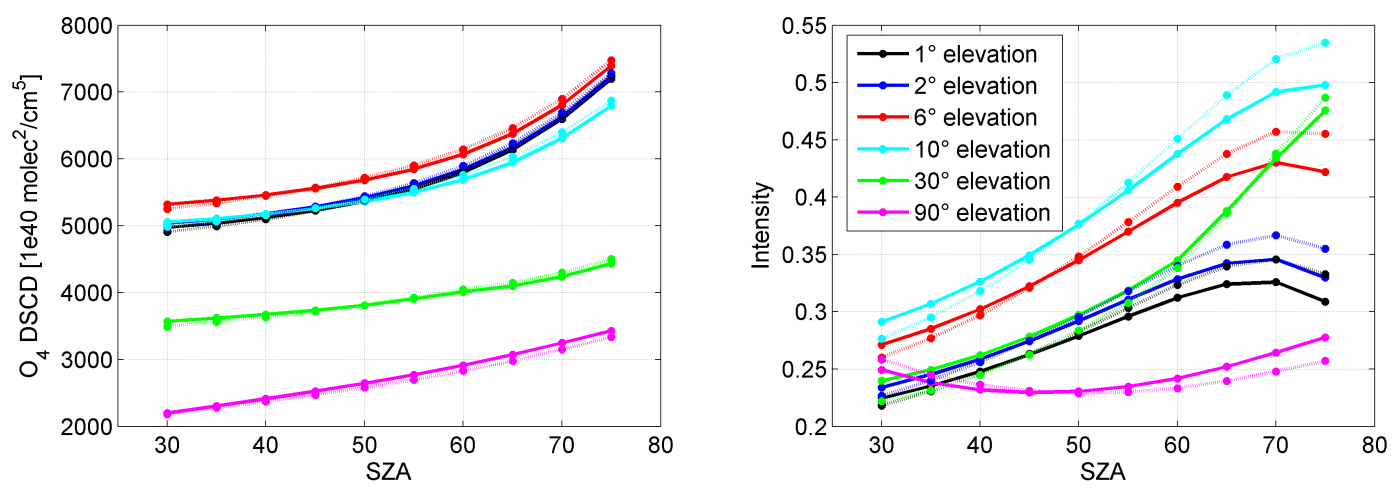

Fig. 6. Illustration of the effect of polarization on the simulation of $\mathrm{O}_{4}$ DSCDs (left) and intensities (right). The solid lines represent the DSCDs and intensities simulated without taking polarization into account, while the dotted lines represent simulations with polarization. The simulations were performed using the DAK code (van de Haan, 1987) for a US standard atmosphere with an aerosol layer having a constant aerosol extinction of $0.1 \mathrm{~km}^{-1}$ from the surface up to $1 \mathrm{~km}$. The single scattering albedo of the aerosol was 0.98 and the asymmetry factor 0.73 . The relative azimuth angle was $180^{\circ}$.

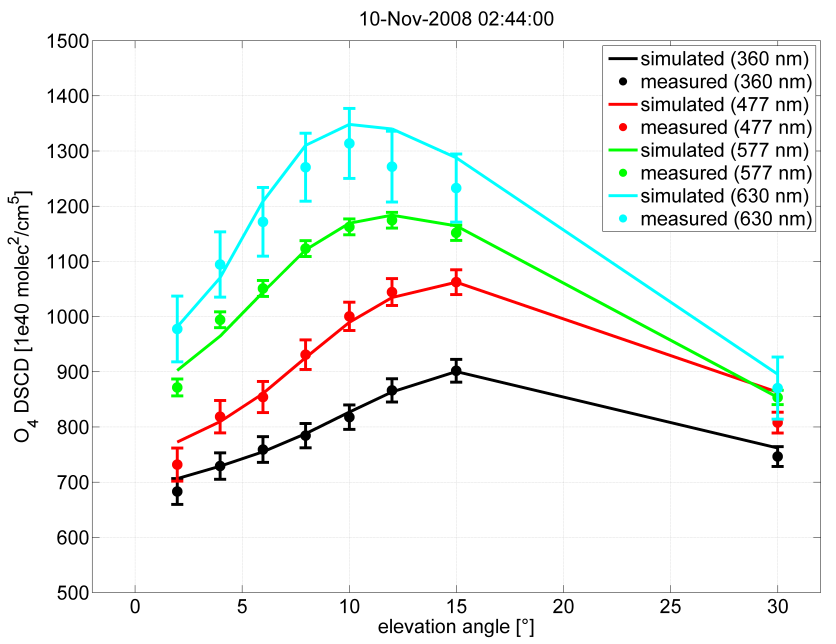

Fig. 7. Comparison between measured $\mathrm{O}_{4}$ DSCDs, on 10 November 2008 at 02:44 UTC, and the DSCDs simulated using the LIDORT radiative transfer code with the retrieved aerosol extinction vertical profiles as input. Error bars shown are the $\mathrm{O}_{4}$ DSCDs DOAS fit errors.

albedo: its uncertainty is a very small source of additional error in the DSCDs (Wittrock et al., 2003; Friess et al., 2006).

To obtain a good estimate of aerosol optical parameters other than the extinction profile (i.e., the single scattering albedo and phase function) we used the AERONET inversion products (size distribution parameters and refractive index) reported on the AERONET website (http://aeronet.gsfc. nasa.gov/) from a co-located CIMEL sunphotometer (Holben et al., 1998), together with a Mie code (de Rooij and van der Stap, 1984) to generate the necessary optical properties. The sunphotometer located in Beijing measures direct and scattered sunlight at 4 different wavelengths $(440,675$, 870 , and $1020 \mathrm{~nm}$ ). No measurements are available in the
UV region. Consequently, the refractive index at $360 \mathrm{~nm}$ has to be extrapolated, while the values at 477,577 , and $630 \mathrm{~nm}$ are linearly interpolated. It should be noted that the AERONET data is automatically cloud screened (Smirnov, 2000). MAXDOAS retrievals, on the other hand, are made for all measurements and thus all atmospheric conditions. In the absence of sunphotometer data, the size distribution parameters and refractive index from the nearest clear-sky day were selected. In situations where no sunphotometer is operated and no other aerosol measurements are available one could opt to use fixed values for the aerosol single scattering albedo and phase function. When reasonable values are chosen (e.g., form a climatology) the retrieval algorithm can still be operated and only small additional errors in the retrieved aerosol extinction profiles are expected.

The AERONET total AODs can be used for a first validation of the aerosol extinction profiles retrieved from the MAXDOAS measurements. Total AODs at 360, 477, 577, and $630 \mathrm{~nm}$ can be extracted using the Ångström coefficient $(\alpha)$, also available on the AERONET website. The Ångström coefficient is defined, for a given wavelength range of total AODs, by a linear regression of total AODs versus wavelength $(\lambda)$ in log-log space (Ångström, 1929; O’Neill et al., 2001):

$\mathrm{AOD}=\beta \times \lambda^{-\alpha}$,

where $\beta$ is the Ångström turbidity factor.

\section{Results and discussion}

\subsection{Aerosol optical properties}

Our algorithm was applied to an extended series of MAXDOAS spectra from June 2008 to April 2009, regardless of the weather conditions. Not all retrievals were successful. To 

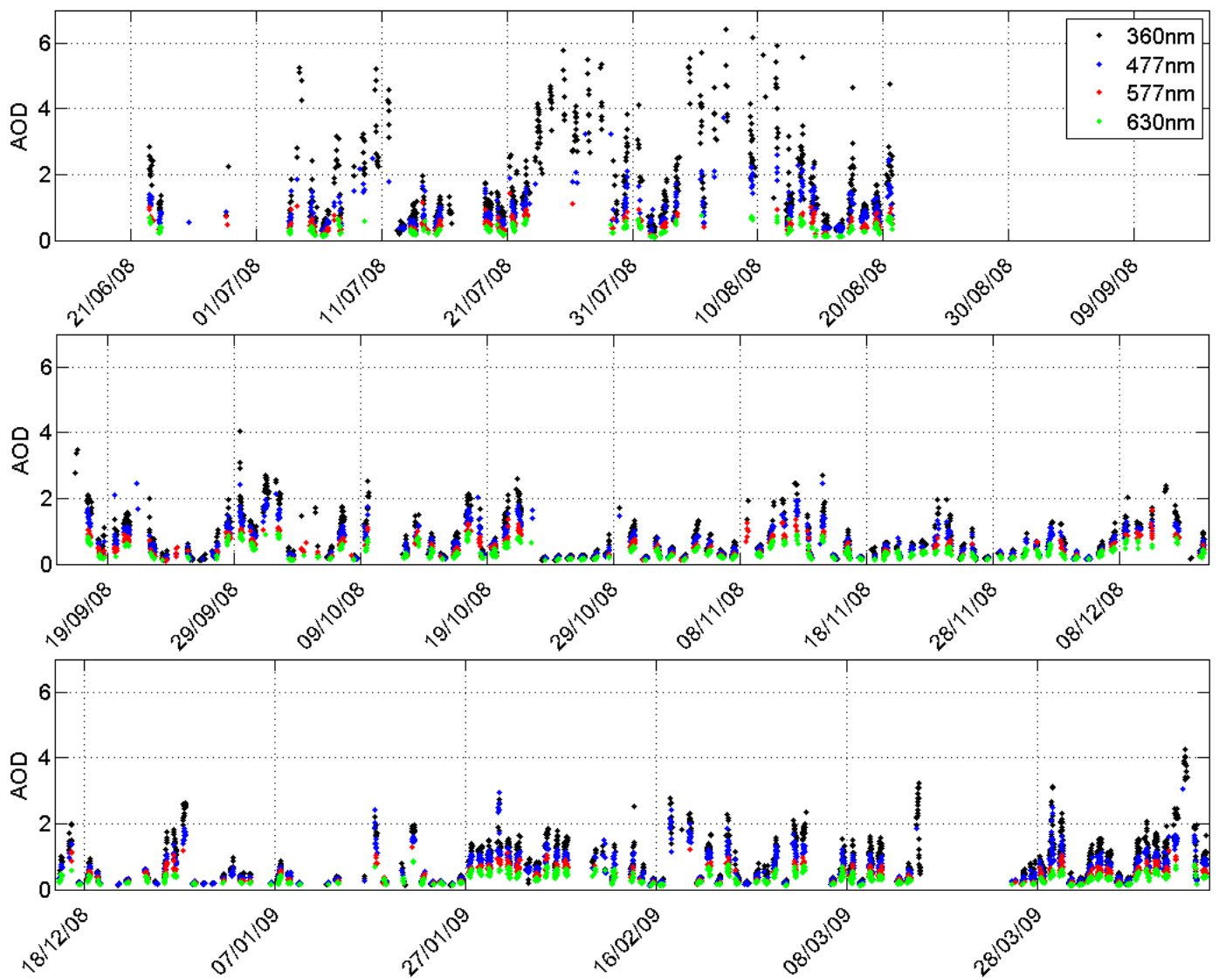

Fig. 8. Time series of the tropospheric total AODs at 360, 477, 577, and $630 \mathrm{~nm}$ retrieved from MAXDOAS measurements made in Beijing from June 2008 to April 2009.

screen the retrievals for quality, we compared the measured $\mathrm{O}_{4}$ DSCDs with the DSCDs simulated using the forward model with the retrieved aerosol as input. Figure 7 compares simulated and retrieved $\mathrm{O}_{4}$ DSCDs for one MAXDOAS scan on 10 November 2008. For each scan, the percent root mean square (RMS) difference between the measured and simulated DSCDs is calculated. We retain only those profiles for which the RMS of the $\mathrm{O}_{4}$ DSCDs is less than $10 \%$. In addition, we checked for the geophysical consistency of the retrieved profiles, i.e., when the retrieved profile exhibits a negative partial column it is rejected. After this screening, $66 \%, 54 \%, 31 \%$, and $40 \%$ of the aerosol profiles are retained at $360,477,577$, and $630 \mathrm{~nm}$, respectively.

The time series of quality-checked total AODs retrieved using the profiling tool at $360,477,577$, and $630 \mathrm{~nm}$ are displayed in Fig. 8. The total AODs were calculated from the corresponding retrieved aerosol extinction vertical profiles. Due to instrumental problems, no MAXDOAS measurements were taken between 21 August and 16 September 2008. From the time series, it can be seen that retrieved total AODs exhibit seasonal variation. Values are larger during the spring and summer, and smaller during autumn and winter. A similar seasonal variation of the total AODs was observed in
Beijing in a study of the total AODs measured by a CIMEL sunphotometer from 2001 until 2004 (Xia et al., 2006). In that work, seasonal changes in total AOD were attributed to changes in the direction of the dominant airflow over Beijing. In winter, clean air from the northwest regions is transported to Beijing, while in summer the airflow over Beijing originates from the southern regions where the total AOD is high.

During June and July 2008, the observed total AODs displayed strong variability. Monthly averages of the retrieved profiles at $360 \mathrm{~nm}$ are displayed in Fig. 9. Most profiles peak at the surface. In June and July 2008, a large aerosol extinction is observed at the surface, 1.6 and $2.1 \mathrm{~km}^{-1}$, respectively. An example of diurnal variation (10 November 2008) of the retrieved profiles at different wavelengths is shown in Fig. 10. This variation is to be expected as a consequence of the build up of the boundary layer during the day (Xia et al., 2006). Surprisingly, this behavior was not typical for Beijing during the MAXDOAS measurement period. In general, the total AODs do not increase during daytime but are more scattered, and no clear monthly averaged diurnal patterns can be distinguished. Similar results were obtained for the total AODs measured by the CIMEL sunphotometer during this period. 


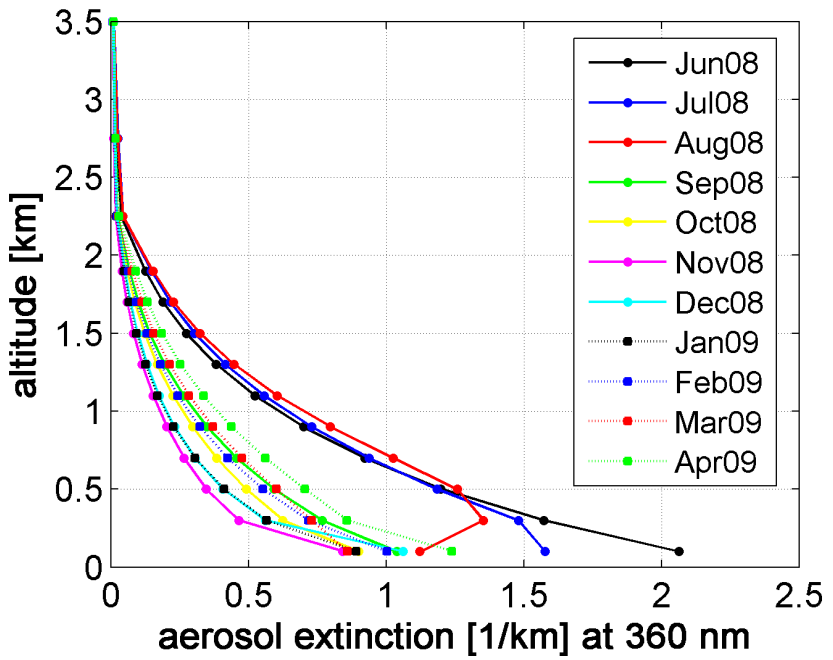

Fig. 9. Monthly mean aerosol extinction profiles at $360 \mathrm{~nm}$ retrieved from the MAXDOAS measurements made in Beijing from June 2008 to April 2009.

\subsection{Characterization of the retrieval}

To obtain information content and error budgets for the retrieval, errors and averaging kernel matrices corresponding to the retrieved profiles were averaged for each wavelength. The results are shown in Fig. 11. The mean DFS values were $1.79,1.89,2.14$, and 1.45 at $360,477,577$, and $630 \mathrm{~nm}$, respectively. It appears that there are 2 independent pieces of information at best. The increase in DFS from 360 to $577 \mathrm{~nm}$ is mainly related to the increase in sensitivity of the retrieval (Friess et al., 2006), due to higher $\mathrm{O}_{4}$ absorption and the higher transparency of the atmosphere at longer wavelengths. However, the DFS also depends on the DOAS fit error through the $\mathbf{S}_{\varepsilon}$ matrix. For the three shorter-wavelength regions, DOAS fit errors were quite comparable, but for the $630 \mathrm{~nm}$ interval, the error was about 4 times larger due to the interference of $\mathrm{H}_{2} \mathrm{O}$ and $\mathrm{O}_{2}$ absorptions and the choice of a relatively narrow wavelength interval (see Fig. 2). Consequently the DFS is smaller.

In Fig. 11 (right), the averaging kernels are shown. The highest sensitivity is in the first layer. The vertical resolution at this altitude is about $250 \mathrm{~m}$. At higher altitudes, the kernels quickly become broader and their peak values decrease. We are mostly sensitive to aerosol below $1 \mathrm{~km}$. However, we note that the averaging kernels depend on the aerosol load. In Beijing most profiles were strongly peaked at the surface. For situations with more aerosol at higher altitudes, the retrieval algorithm shows enhanced sensitivity to aerosol at these altitudes. This is caused by the non-linearity of the inversion problem.

For the calculation of the total retrieval error, shown in Fig. 11 together with the noise and smoothing error, the part caused by forward model errors was neglected. These errors will be discussed separately. The noise (DOAS fitting) error is nearly constant $(\sim 5 \%)$ at all altitudes, and is only a small part of the total error. The smoothing error is the largest contribution, and it is smallest for the lowest layer and increases with altitude. Above $\sim 1.5 \mathrm{~km}$, the total error is larger than $50 \%$. Our error budgets and information content compare reasonably well with the theoretical estimates from Friess et al. (2006).

One of the main forward model error sources is the systematic error on the $\mathrm{O}_{4}$ DSCDs. As discussed in Sect. 2.2, we eliminated this error in an empirical way by determining a correction factor. The effect of this factor on the final retrievals is quite substantial, as illustrated in Fig. 12. Here the scatter plots are shown comparing the AODs retrieved from the uncorrected and corrected $\mathrm{O}_{4}$ DSCDs. Also indicated in Fig. 12 are the bias and the slope of the linear regression fit. For all wavelengths larger AODs are retrieved when applying the correction factor. Other forward model parameters such as the pressure profile, surface albedo, and aerosol single scattering albedo only have a small impact on the retrievals $(<5 \%)$, as has been demonstrated previously (Irie et al., 2008; Friess et al., 2006). The phase function of the aerosol, however, has a larger impact. To determine the exact impact of this parameter aerosol profiles were retrieved using a fixed single scattering albedo (0.8) and a HenyeyGreenstein phase function with a fixed asymmetry parameter of 0.65 in a first run and $0.7(=+10 \%)$ in a second run. The results are represented as scatter plots comparing the AODs of both runs. The plots clearly reveal the substantial impact of the asymmetry parameter on the retrievals. It should be noted that the phase function cannot account for the differences in measured and simulated $\mathrm{O}_{4}$ DSCDs discussed in Sect. 2.2, where it concerned situations with low aerosol load. Under these conditions aerosol optical properties have very little influence on the retrievals.

\subsection{Validation of the retrieval}

To validate the retrievals, we compared hourly averages of the retrieved total AODs with values extracted from a co-located CIMEL sunphotometer. As noted above, the CIMEL-derived total AODs at 360, 477, 577 and $630 \mathrm{~nm}$ are obtained by using the total AODs at 440 and $675 \mathrm{~nm}$ and interpolating by means of Ångström coefficients downloaded from the AERONET website (level 1.5 data). Although the CIMEL data is cloud-screened, MAXDOAS retrievals used in the comparison could still be contaminated by the presence of clouds, as the viewing directions of the sunphotometer and MAXDOAS are different. The CIMEL instrument points towards the sun, while the MAXDOAS instrument is pointing north.

Validation scatter plots are shown in Fig. 14, and linear regression fit parameters and statistical parameters are given in Table 2. A very good correlation is obtained between our retrieved total AODs and those measured by the CIMEL 


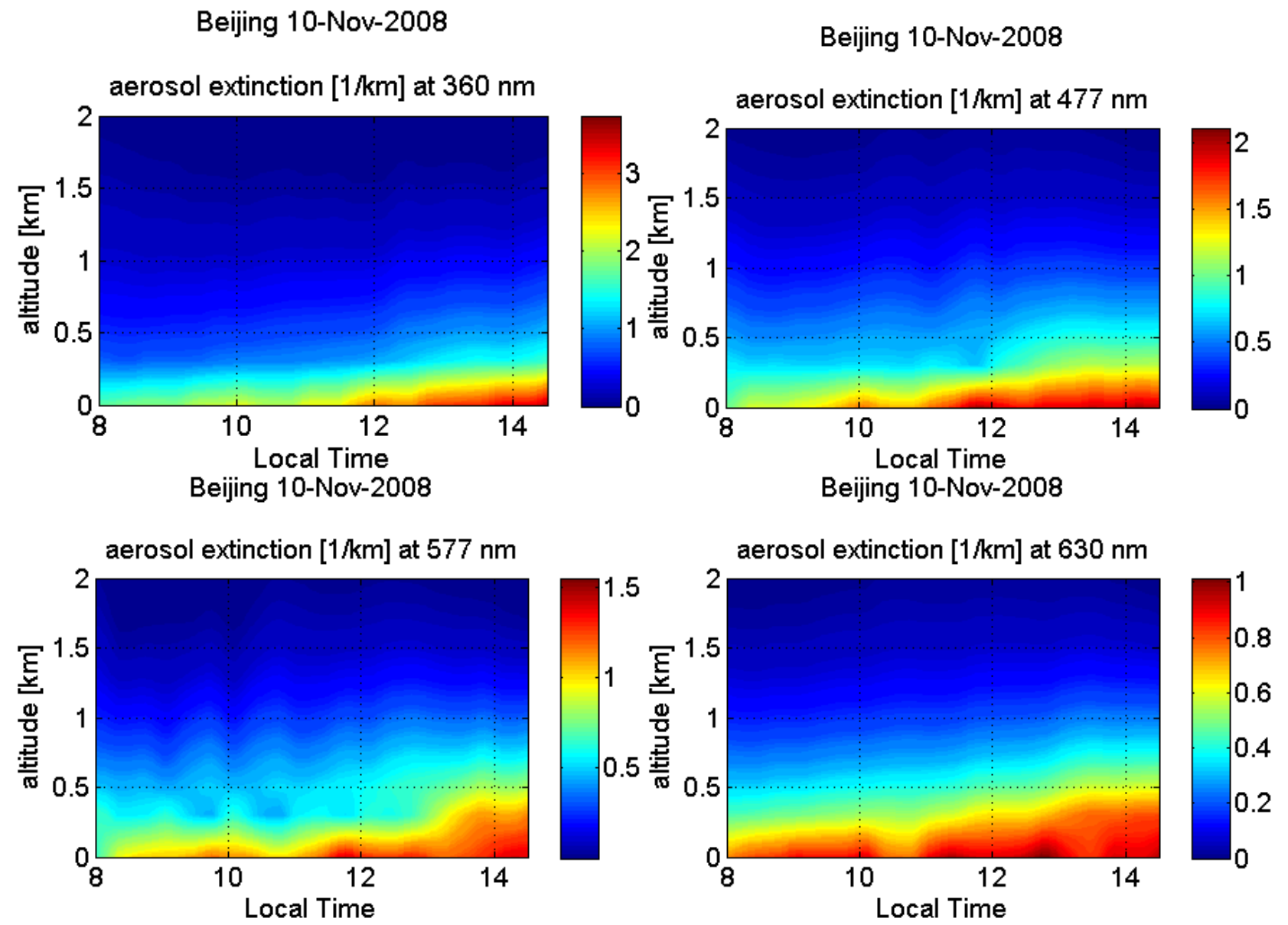

Fig. 10. Diurnal variation of retrieved aerosol extinction profiles on 10 November 2008 in Beijing, shown as contour plots for 360, 477, 577, and $630 \mathrm{~nm}$.

Table 2. Linear regression fit parameters (slope and offset) and statistical parameters (correlation coefficient $R$, bias, standard deviation (stdev), number of points $(N)$ ) for the comparison of the total AODs retrieved from the corrected $\mathrm{O}_{4}$ DSCDs and the values from a sunphotometer in Beijing.

\begin{tabular}{lrrrrrr}
\hline \multicolumn{7}{c}{ Beijing June 2008-April 2009 } \\
Corrected DSCDs & $N$ & Slope & Offset & $R$ & Bias & stdev \\
\hline $360 \mathrm{~nm}$ & 725 & 1.1 & -0.04 & 0.91 & -0.04 & 0.31 \\
$477 \mathrm{~nm}$ & 672 & 1.1 & 0.09 & 0.8 & 0.01 & 0.31 \\
$577 \mathrm{~nm}$ & 410 & 1.3 & -0.08 & 0.72 & -0.06 & 0.29 \\
$630 \mathrm{~nm}$ & 546 & 1.5 & -0.1 & 0.67 & -0.06 & 0.28 \\
\hline
\end{tabular}

instrument. The correlation coefficients $(R)$ decrease with increasing wavelength from 0.91 to 0.67 . The observed biases (mean of the difference between the CIMEL and MAXDOAS values) are quite small. The observed slope (1.1) at 360 and $477 \mathrm{~nm}$ is close to one. For the total AODs at 577 and $630 \mathrm{~nm}$ a slope of, respectively, 1.3 and 1.5 is observed. At these longer wavelengths, the difference between the total AOD values from the MAXDOAS and CIMEL increases with higher total AOD. Possibly the results could still be improved when the correction factor for the $\mathrm{O}_{4}$ DSCDs could be determined with a smaller uncertainty. But using the correction factor, as determined here, already largely improved the results. This is illustrated in Fig. 15 comparing the AODs retrieved from the uncorrected $\mathrm{O}_{4}$ DSCDs with 

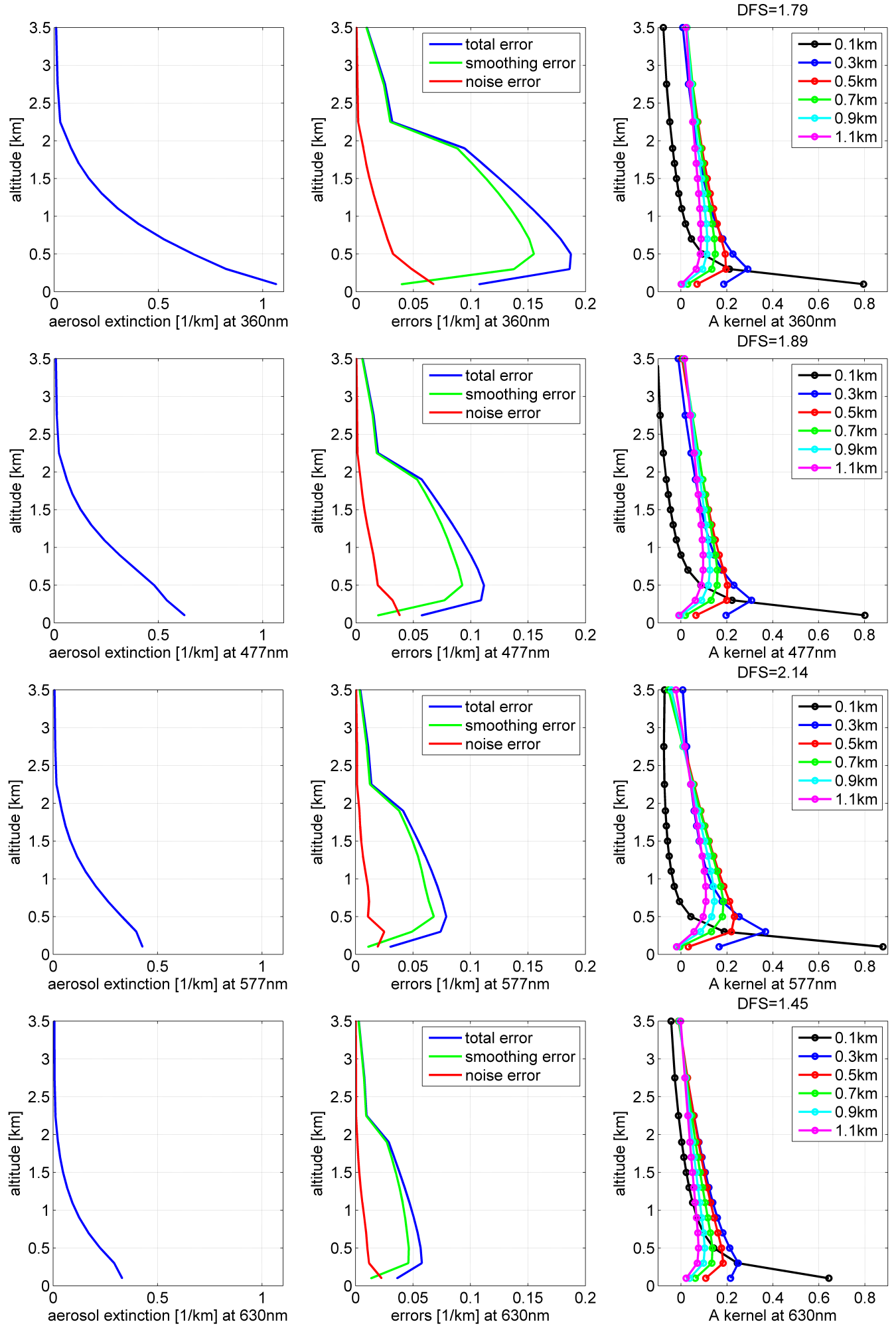

Fig. 11. Mean aerosol extinction profiles (left), error budget (middle), and averaging kernels (right) obtained at 4 wavelengths from the MAXDOAS measurements made in Beijing from June 2008 to April 2009. 

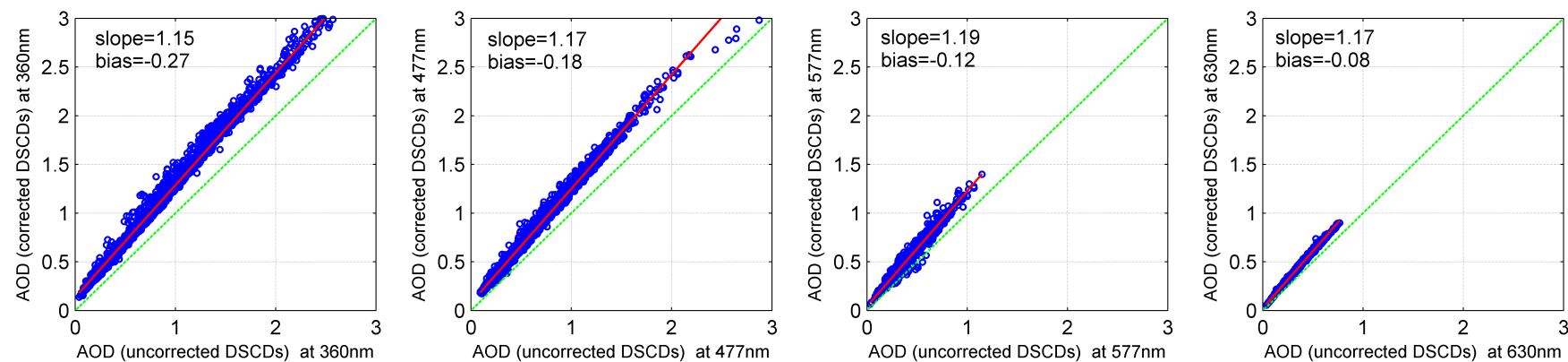

Fig. 12. Scatter plots of the total AODs at 360, 477, 577, and $630 \mathrm{~nm}$ retrieved from the uncorrected and corrected $\mathrm{O}_{4} \mathrm{DSCDs}_{\mathrm{S}}$ obtained from the MAXDOAS measurements in Beijing. Also indicated are the biases and the slopes of the linear regression fits (red lines).
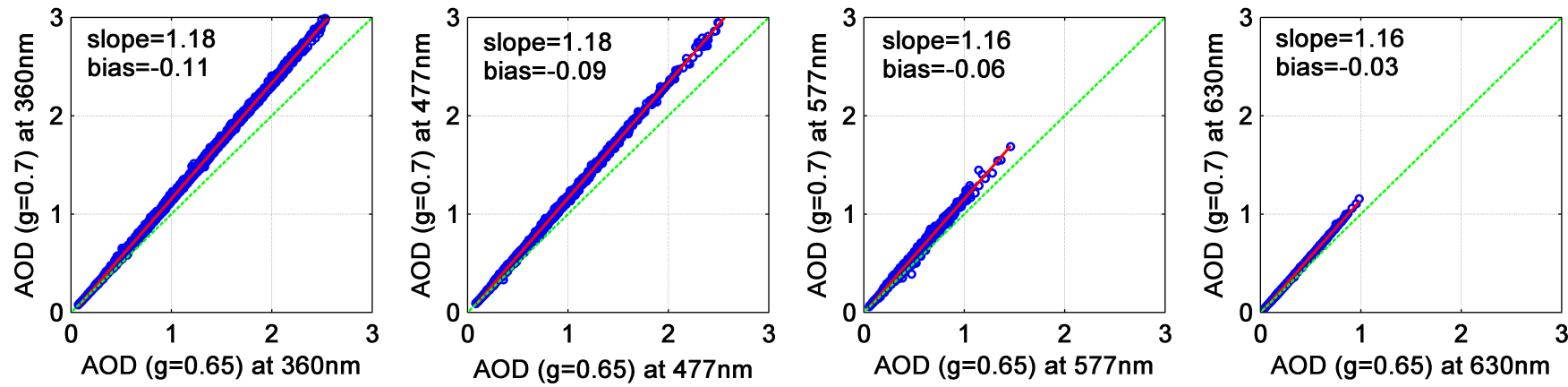

Fig. 13. Scatter plots of the total AODs at 360, 477, 577, and $630 \mathrm{~nm}$ retrieved from the MAXDOAS measurements in Beijing using a constant Henyey-Greenstein phase function with an asymmetry factor $(g)$ of 0.65 versus 0.70 . Also indicated are the biases and the slopes of the linear regression fits (red lines).

the CIMEL values. Table 3 summarises the corresponding statistical parameters. When not applying the correction factor, the RMS of the $\mathrm{O}_{4}$ DSCDs is generally larger and fewer profiles are retained after the quality check. In addition the agreement with the CIMEL values is less good. The correlations are smaller and the slopes and biases are larger for all wavelengths. The differences between the CIMEL AODs and the values obtained from the corrected $\mathrm{O}_{4}$ DSCDs could also possibly be related to an additive error in the $\mathrm{O}_{4}$ DSCDs. The larger the total AOD, the smaller the observed $\mathrm{O}_{4}$ DSCDs (until multiple scattering starts to dominate), and therefore the impact of an additive error would be larger. The additive error could possibly originate from poorly fitted $\mathrm{H}_{2} \mathrm{O}$ and $\mathrm{O}_{2}$, as discussed in Sect. 2.2. Another possible explanation for the observed differences is errors in the phase functions used. Possibly the use of the daily averaged values reported by AERONET is inadequate and the use of more precise phase function data at a higher time resolution is advisable to optimise the results. It is interesting to note that the good agreement is obtained not only for those situations where the total AOD is close to the a priori value, but also in situations where a high aerosol load has been successfully retrieved.

Taking into account the error budget, information content, and the statistical parameters of the validation, the retrieval at $360 \mathrm{~nm}$ (closely followed by that at $477 \mathrm{~nm}$ ) appears to be the most stable and accurate. At longer wavelengths the retrievals were slightly less successful. This may be related to difficulties with the DOAS fitting. It is clearly very important to ensure that the DOAS fittings are of high quality; in particular, systematic errors in the $\mathrm{O}_{4}$ DSCDs have a substantial influence, as illustrated in Figs. 12 and 15. Again, small additive errors, probably caused by interfering absorbers, result in linear regression gradients deviating from 1 in the AOD validation. In addition, the DOAS fit errors are closely related to the DFS of the retrieval.

In the CIMEL-MAXDOAS intercomparison, only retrievals under clear-sky conditions were taken into account. However, we can retrieve aerosol extinction profiles with some success under less ideal circumstances. In scenarios with broken cloud fields, the observed $\mathrm{O}_{4}$ DSCDs display rapid temporal variation. When cloud cover changes in the MAXDOAS field-of-view during a scan, it is very unlikely that the retrieval will be successful. In situations with optically-thin homogeneous cloud cover, it is impossible to distinguish the influence of clouds and tropospheric aerosol on the $\mathrm{O}_{4}$ DSCDs (Wagner et al., 2009). Although an aerosol extinction profile can be determined in these circumstances, it will not represent the real tropospheric aerosol profile. The radiative effect of such an "effective" aerosol 
Table 3. Linear regression fit parameters (slope and offset) and statistical parameters (correlation coefficient $R$, bias, standard deviation (stdev), number of points $(N)$ ) for the comparison of total AODs retrieved from the uncorrected $\mathrm{O}_{4}$ DSCDs and the values from a sunphotometer in Beijing.

\begin{tabular}{lrrrrrr}
\hline \multicolumn{7}{c}{ Beijing June 2008-April 2009 } \\
Uncorrected $\mathrm{O}_{4}$ DSCDs & $N$ & Slope & Offset & $R$ & Bias & stdev \\
\hline $360 \mathrm{~nm}$ & 532 & 1.3 & 0.01 & 0.89 & -0.3 & 0.41 \\
$477 \mathrm{~nm}$ & 515 & 1.4 & -0.04 & 0.8 & -0.2 & 0.38 \\
$577 \mathrm{~nm}$ & 350 & 1.6 & -0.04 & 0.69 & -0.2 & 0.35 \\
$630 \mathrm{~nm}$ & 409 & 1.8 & -0.01 & 0.57 & -0.2 & 0.39 \\
\hline
\end{tabular}
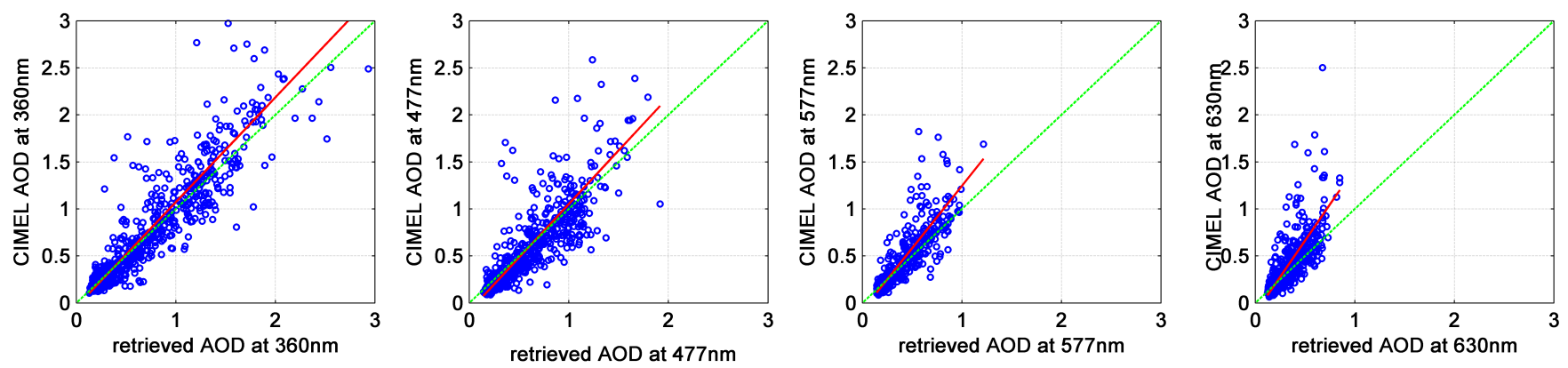

Fig. 14. Scatter plots of the total AODs at 360, 477, 577, and $630 \mathrm{~nm}$ retrieved using the corrected $\mathrm{O}_{4}$ DSCDs from the MAXDOAS measurements in Beijing versus the values from a co-located CIMEL instrument. Also shown are the linear regressions (red lines). Fit parameters and statistics are found in Table 2.
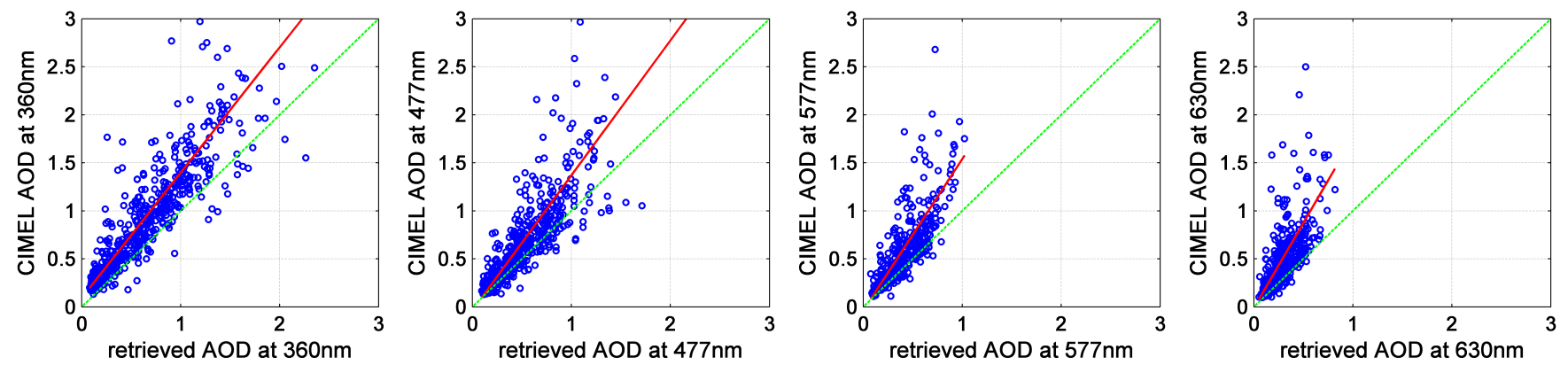

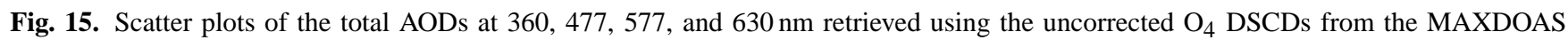
measurements in Beijing versus the values from a co-located CIMEL instrument. Also shown are the linear regressions (red lines). Fit parameters and statistics are found in Table 3.

profile is equivalent to that produced from the combination of clouds and the real tropospheric aerosol loading. These "effective" aerosol profiles are of little value when one is interested in the real tropospheric aerosol burden, but in a future study we might explore whether they could still be useful for the retrieval of trace gases. For the latter application, one is mainly interested in a way to compensate the change in light path caused by the presence of aerosol and clouds. In this case, an "effective" aerosol profile can correct for both aerosol and clouds.

\section{Conclusions}

In this paper, we described a new MAXDOAS instrument developed at BIRA-IASB for the accurate retrieval of aerosol properties and trace gas vertical profiles. We introduced a new algorithm for near real time retrieval of aerosol extinction vertical profiles at four different wavelengths. We outlined a specific approach for the successful automated retrieval of profiles for locations (such as Beijing) where large variability of total AODs is evident.

Results were presented for MAXDOAS measurements made in Beijing from June 2008 to April 2009. We confirmed 
that the retrieval is most sensitive to aerosol close to the surface with a vertical resolution of around $250 \mathrm{~m}$, and that the sensitivity, as well as the vertical resolution, decreases rapidly with altitude. Measurements contain about 1.5 to 2 independent pieces of information. The main sources of error are the smoothing error and the uncertainties in the aerosol phase function. We determined a correction factor for the $\mathrm{O}_{4}$ DSCDs and demonstrated how this factor can substantially improve the retrievals. Retrieved total AODs at 360, 477, 577 , and $630 \mathrm{~nm}$ have been validated through comparison with correlative sunphotometer measurements. Good correlations (0.67-0.9) and acceptable standard deviations $(\sim 0.3)$ were obtained.

We showed that the best results were obtained for the shorter wavelengths ( 360 and $477 \mathrm{~nm}$ ). At $630 \mathrm{~nm}$ the enhanced DOAS fit errors are responsible for a substantial reduction of the information content. We also demonstrated the impact of additive errors in the $\mathrm{O}_{4}$ DSCDs. Another conclusion is the need for more accurate DOAS fitting at the longer wavelength.

The results of the present work strongly indicate that MAXDOAS measurements can ultimately be used to provide high-quality long-term time series of aerosol extinction profiles. In the future the retrieval algorithm could be extended to other aerosol properties such as, e.g., single scattering albedo and phase function. This could be accomplished through combining the $\mathrm{O}_{4}$ DSCDs with the relative intensities, that are more sensitive to the single scattering albedo and phase function (Friess et al., 2006), and the Ring effect, which contains complementary information on the phase function and stratospheric aerosol (Wagner et al., 2009). In those cases the effect of polarization needs to be included in the radiative transfer simulation. Additional information could also be obtained from the direct sun measurements and almucantar scans.

Moreover, these MAXDOAS measurements and our retrieval algorithm can be used for the retrieval of vertical profiles of trace gases such as $\mathrm{NO}_{2}$, formaldehyde, glyoxal, $\mathrm{SO}_{2}$, $\mathrm{O}_{3}$, and $\mathrm{BrO}$ that are present close to the surface. One of the main obstacles for tropospheric trace gas vertical profile retrievals from MAXDOAS measurements is high sensitivity of the length of the light path - and thus the observed DSCD of an atmospheric absorber - to the presence of aerosol in the atmosphere (Heckel et al., 2005; Wittrock et al., 2004; Sinreich et al., 2005; Irie et al., 2009). Our retrieval algorithm for aerosol information is an excellent point of departure for the development of a more general algorithm for the near real time retrieval of aerosol extinction and trace gas vertical profiles.

Acknowledgements. This research was financially supported by the Belgian Federal Science Policy Office through the AGACC project (contract SD/AT/01A and SD/AT/01B), as well as by the European Commission through the GEOmon (Global Earth Observation and Monitoring) Integrated Project under the 6th Framework Program (contract number FP6-2005-Global-4-036677) and the
AMFIC project. We thank H. B. Chen, P. Goloub and their staff for establishing and maintaining the Beijing AERONET site used in this study. P. Stammes (KNMI) is acknowledged for providing us with the DAK code and the KNMI Mie code, and for the fruitful discussions with the authors.

Edited by: G. Pappalardo

\section{References}

Ångström, A.: On the atmospheric transmission of sun radiation and on dust in the air, Geogr. Ann. Dtsch., 12, 156-166, 1929.

Barret, B., De Maziere, M. D., and Demoulin, P.: Retrieval and characterization of ozone profiles from solar infrared spectra at the Jung-fraujoch, J. Geophys. Res. 107(D24), 4788, doi:10.1029/2001JD001298, 2002.

Bogumil, K., Orphal, J., Homann, T., Voigt, S., Spietz, P., Fleischmann, O. C., Vogel, A., Hartmann, M., Bovensmann, H., Frerik, J., and Burrows, J. P.: Measurements of molecular absorption spectra with the SCIAMACHY Pre-Flight Model: Instrument characterization and reference spectra for atmospheric remote sensing in the $230-2380 \mathrm{~nm}$ region, J. Photochem. Photobiol. A, 157, 167-184, 2003.

Chance, K. and Spurr, R. J. D.: Ring effect studies: Rayleigh scattering including molecular parameters for rotational Raman scattering, and the Fraunhofer spectrum, Appl. Optics, 36, 52245230, 1997.

de Rooij, W. A. and van der Stap, C.: expansion of Mie scattering matrices in generalized spherical functions, Astron. Astrophys., 131, 237-248, 1984.

Fayt, C. and Van Roozendael, M.: WINDOAS user manual, http://www.oma.be/BIRA-IASB/Molecules/BrO/ WinDOAS-SUM-210b.pdf, 2001.

Friess, U., Monks, P. S., Remedios, J. J., Rozanov, A., Sinreich, R., Wagner, T., and Platt, U.: MAX-DOAS $\mathrm{O}_{4}$ measurements: A new technique to derive information on atmospheric aerosols: 2. Modeling studies, J. Geophys. Res., 111, D14203, doi:10.1029/2005JD006618, 2006.

Greenblatt, G. D., Orlando, J. J., Burkholder, J. B., and Ravishankara, A. R.: Absorption measurements of oxygen between 330 and 1140 nm, J. Geophys. Res., 95, 18577-18582, 1990.

Haan de, J., Bosma, P., and Hovenier, J.: The adding method for multiple scattering computations of polarized light, Astron. Astrophys., 183, 371-391, 1987.

Heckel, A., Richter, A., Tarsu, T., Wittrock, F., Hak, C., Pundt, I., Junkermann, W., and Burrows, J. P.: MAX-DOAS measurements of formaldehyde in the Po-Valley, Atmos. Chem. Phys., 5, 909918, doi:10.5194/acp-5-909-2005, 2005.

Hendrick, F., Barret, B., Van Roozendael, M., Boesch, H., Butz, A., De Mazière, M., Goutail, F., Hermans, C., Lambert, J.C., Pfeilsticker, K., and Pommereau, J.-P.: Retrieval of nitrogen dioxide stratospheric profiles from ground-based zenith-sky UV-visible observations: validation of the technique through correlative comparisons, Atmos. Chem. Phys., 4, 2091-2106, doi:10.5194/acp-4-2091-2004, 2004.

Holben, B. N., Eck, T. F., Slutsker, I., Tanre, D., Buis, J. P., Setzer, A., Vermote, E., Reagan, J. A., Kaufman, Y. J., Nakajima, T., Lavenu, F., Jankowiak, I., and Smimov, A.: AERONET -A 
federated instrument network and data archive for aerosol characterization, Rem. Sens. Environ., 66(1), 1-16, 1998.

Hönninger, G., von Friedeburg, C., and Platt, U.: Multi axis differential optical absorption spectroscopy (MAX-DOAS), Atmos. Chem. Phys., 4, 231-254, doi:10.5194/acp-4-231-2004, 2004.

Ipcc 2007: Intergovernmental Panel on Climate Change, Fourth Assessment Report, 2007.

Irie, H., Kanaya, Y., Akimoto, H., Iwabuchi, H., Shimizu, A., and Aoki, K.: First retrieval of tropospheric aerosol profiles using MAX-DOAS and comparison with lidar and sky radiometer measurements, Atmos. Chem. Phys., 8, 341-350, doi:10.5194/acp-8341-2008, 2008.

Irie, H., Kanaya, Y., Akimoto, H., Iwabuchi, H., Shimizu, A., and Aoki, K.: Dual-wavelength aerosol vertical profile measurements by MAX-DOAS at Tsukuba, Japan, Atmos. Chem. Phys., 9, 2741-2749, doi:10.5194/acp-9-2741-2009, 2009.

Irie, H., Kanaya, Y., Takashima, H., Gleason, J. F., and Wang, Z.: Characterization of OMI Tropospheric $\mathrm{NO}_{2}$ Measurements in East Asia Based on a Robust Validation Comparison, SOLA, 5, 117-120, doi:10.2151/sola.2009-030, 2009.

Koelemeijer, R. B. A., de Haan, J. F., and Stammes, P.: A database of spectral surface reflectivity in the range $335-772 \mathrm{~nm}$ derived from 5.5 years of GOME observations, J. Geophys. Res., 108(D2), 4070, doi:10.1029/2002JD002429, 2003.

Li, X., Brauers, T., Shao, M., Garland, R. M., Wagner, T., Deutschmann, T., and Wahner, A.: MAX-DOAS measurements in southern China: retrieval of aerosol extinctions and validation using ground-based in-situ data, Atmos. Chem. Phys., 10, 20792089, doi:10.5194/acp-10-2079-2010, 2010.

Meller, R. and Moortgat, G. K.: Temperature dependence of the absorption cross-sections of formaldehyde between 223 and $323 \mathrm{~K}$ in the wavelength range $225-375 \mathrm{~nm}$, J. Geophys. Res., 105, 7089-7101, 2000.

O’Neill, N. T., Dubovik, O., and Eck, T.: Modified Ångström exponent for the characterization of submicrometer aerosols, Appl. Optics, 40, 2368-2375, 2001.

Perner, D. and Platt, U.: Absorption of light in the atmosphere by collision induced pairs of oxygen, $\left(\mathrm{O}_{2}\right)_{2}$, Geophys. Res. Lett., 7, 1053-1056, 1980.

Platt, U.: Differential optical absorption spectroscopy (DOAS), in Air Monitoring by Spectroscopic Techniques, vol. 127, John Wiley, Hoboken, NY, 27-83, 1994.

Platt, U. and Stutz, J.: Differential Optical Absorption Spectroscopy: Principles and Applications, Springer-Verlag, Berlin, 2008.

Rodgers, C. D.: Inverse Methods for Atmospheric Sounding: Theory and Practice, Ser. Atmos. Oceanic Planet. Phys., vol. 2, F.W. Taylor, World Sci., Hackensack, NY, 2000.

Rothman, L. S., Gordon, I. E., Barbe, A., Chris Benner, D., Bernath, P. F., Birk, M., Boudon, V., Brown, L. R., Campargue, A., Champion, J.-P., Chance, K., Coudert, L. H., Danaj, V., Devi, V. M., Fally, S., Flaud, J.-M., Gamache, R. R., Goldmanm, A., Jacquemart, D., Kleiner, I., Lacome, N., Lafferty, W. J., Mandin, J.-Y., Massie, S. T., Mikhailenko, S. N., Miller, C. E., Moazzen-Ahmadi, N., Naumenko, O. V., Nikitin, A. V., Orphal, J., Perevalov, V. I., Perrin, A., Predoi-Cross, A., Rinsland, C. P., Rotger, M., Imeckova, M. S, Smith, M. A. H., Sung, K., Tashkun, S. A., Tennyson, J., Toth, R. A., Vandaele, A. C., and VanderAuwera, J.: The HITRAN 2008 molecular spectroscopic database, J. Quant. Spectr. Radiat. T., 110, 533-572, 2009.

Sinreich, R., Friess, U., Wagner, T., and Platt, U.: Multi axis differential absorption spectroscopy (MAXDOAS) of gas and aerosol distributions, Faraday Discuss., 130, 153-164, 2005.

Smirnov, A., Holben, B. N., Eck, T. F., Dubovik, O., and Slutsker, I.: Cloud screening and quality control algorithms for the AERONET database, Remote Sens. Environ., 73, 337-349, 2000.

Spurr, R.: LIDORT and VLIDORT: Linearized pseudo-spherical scalar and vector discrete ordinate radiative transfer models for use in remote sensing retrieval problems, Light Scattering Reviews, Volume 3, edited by: Kokhanovsky, A., Springer, 2008.

Stammes, P.: Spectral radiance modelling in the UV-Visible range. IRS 2000: Current problems in Atmospheric Radiation, edited by: Smith, W. L. and Timofeyev, Y. M., A. Deepak, Hampton, VA, 385-388, 2001.

Vandaele, A. C., Hermans, C., Simon, P. C., Carleer, M., Colin, R., Fally, S., Me'rienne, M.-F., Jenouvrier, A., and Coquart, B.: Measurements of the NO2 absorption cross-section from $42000 \mathrm{~cm}^{-1}$ to $10000 \mathrm{~cm}^{-1}(238-1000 \mathrm{~nm})$ at $220 \mathrm{~K}$ and 294 K, J. Quant. Spectrosc. Radiat. T., 59, 171-184, 1998.

Van Roozendael, M., Fayt, C., Lambert, J.-C., Pundt, I., Wagner, T., Richter, A., and Chance, K.: Development of a bromine oxide product from GOME, European Symposium on Atmosph. Measurements from Space, ESA WPP-161, 543-547, 1999.

Volkamer, R.: Absorption von Sauerstoff im Herzberg I System, und Anwendungen auf die Aromatenmessungen am European PHoto Reactor, (EUPHORE), Diploma thesis, Univ. Of Heidelberg, Germany, 1996.

Wagner, T., von Friedeburg, C., Wenig, M., Otten, C., and Platt, $\mathrm{U}$.: UV-visible observations of atmospheric $\mathrm{O}_{4}$ absorptions using direct moonlight and zenith-scattered sunlight for clearsky and cloudy sky conditions, J. Geophys Res., 107, 4424, doi:10.1029/2001JD001026, 2002.

Wagner, T., Dix, B., Friedeburg, v. C., Friess, U., Sanghavi, S., Sinreich, R., and Platt, U.: MAX-DOAS $\mathrm{O}_{4}$ measurements: A new technique to derive information on atmospheric aerosols Principles and information content, J. Geophys. Res., 109, D22205, doi:10.1029/2004JD004904, 2004.

Wagner, T., Deutschmann, T., and Platt, U.: Determination of aerosol properties from MAX-DOAS observations of the Ring effect, Atmos. Meas. Tech., 2, 495-512, doi:10.5194/amt-2-4952009, 2009.

Wilmouth, D. M., Hanisco, T. F., Donahue, N. M., and Anderson, J. G.: Fourier transform ultraviolet spectroscopy of the $\mathrm{A}_{3 / 2}^{2 \pi} \leftarrow \mathrm{X}_{3 / 2}^{2 \pi}$ transition of BrO, J. Phys. Chem. A., 103, 8935$8945,1999$.

Wittrock, F., Oetjen, H., Richter, A., Fietkau, S., Medeke, T., Rozanov, A., and Burrows, J. P.: MAX-DOAS measurements of atmospheric trace gases in Ny-Ålesund - Radiative transfer studies and their application, Atmos. Chem. Phys., 4, 955-966, doi:10.5194/acp-4-955-2004, 2004.

Xia, X. A., Chen, H. B., Wang, P. C., Zhang, W. X., Goloub, P. Chatenet, B., Eck, T. F., and Holben, B. N.: Variation of columnintegrated aerosol properties in a Chinese urban region, J. Geophys. Res., 111, D05204, doi:10.1029/2005JD006203, 2006. 